\title{
Avaliação da qualidade do caldo extraído de toletes de cana-de-açúcar minimamente processada, armazenados sob diferentes temperaturas
}

\author{
Evaluation of the quality of the juice extracted of pieces of \\ fresh cut sugar cane stored under different temperatures
}

\author{
Silvana Rodrigues Rabelo de ANDRADE ${ }^{1 \star}$, Ernani PORTO $^{1}$, Marta Helena Fillet SPOTO ${ }^{1}$
}

\begin{abstract}
Resumo
O presente trabalho visou avaliar a qualidade físico-química e microbiológica do caldo extraído de toletes de cana-de-açúcar minimamente processada, armazenados sob três temperaturas. Colmos de cana-de-açúcar foram minimamente processados na forma de toletes com $60 \mathrm{~cm}$ de comprimento, higienizados e acondicionados em embalagens de polietileno de baixa densidade. Cada embalagem acondicionou 12 toletes de cana-de-açúcar devidamente higienizados. Em seguida, procedeu-se o armazenamento das embalagens sob três temperaturas: ambiente $\left(22\right.$ a $\left.25^{\circ} \mathrm{C}\right)$, utilizada como controle, refrigeração $\left(4^{\circ} \mathrm{C}\right)$ e congelamento $\left(-20^{\circ} \mathrm{C}\right)$. Foram avaliadas a qualidade físico-química do caldo e a sua composição microbiológica, em intervalos de 6 dias, durante 24 dias de armazenamento. $\mathrm{O}$ caldo extraído dos toletes armazenados sob congelamento apresentou boa qualidade físico-química e microbiológica durante todo o período avaliado. Por outro lado, o caldo extraído dos toletes armazenados sob refrigeração e o controle apresentaram elevadas alterações microbiológicas, limitando o período de conservação dos toletes até 12 e 6 dias, respectivamente, o que permitiu concluir que o tratamento mais eficiente para a preservação da qualidade do caldo foi o congelamento da cana-de-açúcar minimamente processada.
\end{abstract}

Palavras-chave: cana-de-açúcar; processamento mínimo; caldo; armazenamento.

\begin{abstract}
The present work aimed at evaluating the microbiological and physicochemical quality of fresh cut sugar cane juice. Sugar cane stalks were cut in pieces of $60 \mathrm{~cm}$ of length, sanitized, and conditioned in polyethylene packaging of low density. Each package conditioned 12 pieces of sanitized sugar can. After that, they were stored at three different temperatures: room temperature $\left(22-25^{\circ} \mathrm{C}\right)$, used as control, refrigeration $\left(4^{\circ} \mathrm{C}\right)$, and freezing $\left(-20^{\circ} \mathrm{C}\right)$. The microbiological and physicochemical quality of the juice was evaluated every 6 days of storage for 24 days. The sugar cane juice stored under freezing temperatures presented good quality for all microbiological and physicochemical parameters during the period evaluated. On the other hand, the sugar cane stored juice under refrigeration and the controls presented high microbiological alterations reducing their period of conservation to 12 and 6 days, respectively. It can be conclude that the most efficient treatment for the preservation of the fresh cut sugar cane shelf life was under freezing temperature.
\end{abstract}

Keywords: fresh cut sugar cane; juice; shelf-life.

\section{Introdução}

Atualmente a comercialização de caldo de cana-de-açúcar tem se mostrado bastante precária devido, principalmente, à falta de práticas higiênico-sanitárias adequadas nas etapas de despalhamento, descascamento e corte da cana. Geralmente, os processos citados são realizados com instrumentos inadequados para manipulação de alimentos, como foices e facas não higienizadas e sanificadas adequadamente.

Segundo Gallo (1989), procedimentos inadequados no manuseio de um produto alimentício, sob o ponto de vista higiênico-sanitário, comprometem a saúde humana, principalmente quando se trata da cana-de-açúcar, que possui alta atividade de água, $\mathrm{pH}$ e temperatura favoráveis, tornando-se um meio propício para o desenvolvimento microbiano.

Desta forma, a técnica de processamento mínimo surge como alternativa para a obtenção de um produto de elevado grau de frescor, sanidade e alta praticidade, possibilitando a diminuição do tempo de preparo e a elevação do padrão de qualidade do produto (WILEY, 1997). Segundo IFPA (2006), os produtos minimamente processados são caracterizados como aqueles que sofreram alguma alteração em sua condição natural, como o descascamento, corte ou fatiamento, lavagem, sanificação, drenagem e acondicionamento em embalagem, mas que mantêm estado de frescor semelhante aos produtos in natura.

Segundo Gonzalez (2006), o emprego de baixa temperatura deve ser aplicado em toda a cadeia de comercialização, ou seja, durante o processamento, armazenamento e comercialização, uma vez que minimiza alterações fisiológicas indesejáveis e possibilita a elevação da vida útil de frutas e vegetais minimamente processados.

Recebido para publicação em 1/4/2007

Aceito para publicação em 18/5/2008 (002435)

'Departamento de Agroindústria, Alimentos e Nutrição, Escola Superior de Agricultura "Luiz de Queiroz" - ESALQ, Universidade de São Paulo - USP, Piracicaba - SP, Brasil, E-mail: sil.uni@gmail.com

${ }^{*}$ A quem a correspondência deve ser enviada 
A diminuição da temperatura do produto vegetal, durante o processamento e armazenamento, é fundamental para reduzir a respiração, a produção de etileno e a transpiração, ou seja, as deteriorações fisiológicas, bem como colabora para a diminuição da microbiota. Apesar do uso da refrigeração ser indispensável, para cada tipo de produto, existe a faixa de temperatura adequada para conservação e prolongamento da vida útil do produto (WILEY, 1997).

Sendo assim, levando-se em consideração os fatores acima citados, o presente trabalho teve como objetivo avaliar a qualidade físico-química e microbiológica do caldo extraído de toletes de cana-de-açúcar minimamente processada, armazenados sob três temperaturas: ambiente (controle), refrigeração e congelamento.

\section{Material e métodos}

Para o experimento foram utilizados 320 colmos de canade-açúcar (Saccharum officinarum L.), pertencentes à variedade SP-3281, obtidos na Fazenda Areão, localizada na cidade de Piracicaba, estado de São Paulo. Os colmos foram levados à Planta Piloto do Departamento de Agroindústria, Alimentos e Nutrição da ESALQ/USP, submetidos ao despalhamento e, posteriormente, lavados com detergente neutro para a retirada das sujidades. Em seguida, os colmos tiveram sua casca retirada com uso de descascador automático, da marca Maqtron, e com auxílio de facas, afiadas e sanitizadas com solução sanificante de cloro (Dicloro S-Triazinatriona Sódica Diadratada 3\%) na concentração de $200 \mathrm{mg} . \mathrm{L}^{-1}$ de cloro livre, foram cortados em toletes de $60 \mathrm{~cm}$ de comprimento. Os toletes foram imersos em solução sanificante de cloro, com concentração de $80 \mathrm{mg} . \mathrm{L}^{-1}$ de cloro livre durante 5 minutos. Seguiu-se a drenagem por 3 minutos e o acondicionamento em embalagens de polietileno de baixa densidade, com 12 toletes em cada embalagem. Uma parte das embalagens foi armazenada sob temperatura ambiente (22 a $25^{\circ} \mathrm{C}$ ) usada como controle, uma segunda parte sob refrigeração $\left(4^{\circ} \mathrm{C}\right)$ e a terceira parte sob congelamento $\left(-20^{\circ} \mathrm{C}\right)$.

\subsection{Análises}

As análises físico-químicas foram realizadas a cada 6 dias, totalizando 24 dias de armazenamento. Para isso, os toletes acondicionados em cada embalagem foram triturados em máquina da marca Maqtron, para extração do caldo de cana-de-açúcar de cada tratamento. As análises realizadas foram: $\mathrm{pH}$ - a partir de amostras liquefeitas foi usado o potenciômetro DIGIMED modelo DMPH, segundo metodologia proposta por Carvalho (1990); acidez titulável - foi determinada por titulação com $\mathrm{NaOH}$ 0,1 N até pH 8,1, com os resultados expressos em g ácido cítrico $100 \mathrm{~g}^{-1}$ da polpa (CARVALHO et al., 1990); teor de sólidos solúveis - determinado por metodologia proposta por Carvalho et al. (1990), que utilizam um refratômetro digital manual Atago, com leituras expressas em ${ }^{\circ}$ Brix.

A investigação da contagem de bolores, leveduras e enterobactérias, inicialmente presentes nas amostras foi feita a partir do caldo de cana obtido de toletes não sanitizados, segundo Vanderzant e Splittstoesser (1992). Uma alíquota de $500 \mathrm{~mL}$ do caldo de cana foi recolhida em frasco estéril e submetida às diluições decimais pertinentes em água salina peptonada. Para a contagem de bolores e leveduras, foi utilizado o método de plaqueamento em profundidade, inoculando-se, em triplicata, $1 \mathrm{~mL}$ de três diluições da amostra, em placas de Petri estéreis. Posteriormente, verteu-se nas placas cerca de 15 a $20 \mathrm{~mL}$ de ágar Padrão para Contagem (PCA) suplementado com $100 \mathrm{mg} . \mathrm{L}^{-1}$ de cloranfenicol, conforme Vanderzant e Splittstoesser (1992), homogeneizando-se o inóculo com movimentos suaves rotatórios, numa superfície plana. Após a solidificação do meio, as placas foram incubadas a $25^{\circ} \mathrm{C}$ por 5 dias. Foram consideradas para a contagem as placas contendo entre 25 e 250 colônias, sendo contadas separadamente as colônias de leveduras e bolores. Para a contagem de coliformes totais utilizou-se o método de plaqueamento em ágar Vermelho Violeta Bile (VRB), o qual utilizou procedimento semelhante ao realizado para a contagem de bolores e leveduras, incubando-se, porém, a $35^{\circ} \mathrm{C}$ por 48 horas e considerando-se como típicas as colônias contendo cor vermelho-violeta.

\subsection{Análise estatística}

O delineamento empregado foi inteiramente casualizado com esquema fatorial do tipo $3 \times 5$ e três repetições. Os fatores foram constituídos de 3 intervalos de temperatura (ambiente, 22 a $25{ }^{\circ} \mathrm{C}$; refrigeração, $4{ }^{\circ} \mathrm{C}$; e congelamento, $-20{ }^{\circ} \mathrm{C}$ ) e 5 períodos de armazenamento $(1 ; 6 ; 12 ; 18$; e 24 dias $)$. As unidades amostrais foram constituídas do caldo de cana-de-açúcar obtido a partir da trituração dos 12 toletes acondicionados em cada embalagem. Os resultados foram submetidos à análise de variância pelo teste $F$ e a comparação das médias pelo teste de Tukey (5\%), pelo programa estatístico Sanest (ZONTA; MACHADO, 1985).

\section{Resultados e discussão}

\subsection{Análise físico-química}

Foi observado, ao longo do período de armazenamento, o abaixamento do $\mathrm{pH}$ do caldo de cana-de-açúcar, em todos os tratamentos, porém apenas o caldo obtido dos toletes armazenados sob temperatura ambiente alcançou queda significativa a partir do $12^{\circ}$ dia de armazenamento, quando comparado ao $1^{\circ}$ dia e aos demais tratamentos. Para o caldo obtido dos toletes sob refrigeração e congelamento foi observada queda gradual, porém pouco significativa entre si (Tabela 1 ).

Esta queda de $\mathrm{pH}$ está associada diretamente ao aumento da acidez titulável, principalmente quando se consideram os toletes sob temperatura ambiente (controle), nos quais foram

Tabela 1. Valores médios de $\mathrm{pH}$ do caldo de cana durante o armazenamento dos toletes sob três intervalos de temperatura.

\begin{tabular}{cccccc}
\hline $\begin{array}{c}\text { Temperatura de } \\
\text { estocagem }\left({ }^{\circ} \mathrm{C}\right)\end{array}$ & $1^{\circ}$ dia & $6^{\circ}$ dia & $12^{\circ}$ dia & $18^{\circ}$ dia & $24^{\circ}$ dia \\
\hline $22-25$ & $5,25^{\mathrm{Aa}}$ & $4,96^{\mathrm{Aa}}$ & $4,35^{\mathrm{Bb}}$ & $4,35^{\mathrm{Bb}}$ & $3,98^{\mathrm{Bb}}$ \\
4 & $5,32^{\mathrm{Aa}}$ & $5,16^{\mathrm{ABa}}$ & $4,92^{\mathrm{BCa}}$ & $4,92^{\mathrm{BCa}}$ & $4,54^{\mathrm{Ca}}$ \\
-20 & $5,30^{\mathrm{Aa}}$ & $5,16^{\mathrm{ABa}}$ & $4,99^{\mathrm{ABa}}$ & $4,99^{\mathrm{ABa}}$ & $4,84^{\mathrm{Ba}}$ \\
\hline
\end{tabular}

${ }^{*}$ Médias seguidas por letras distintas, maiúsculas nas linhas e minúsculas nas colunas, diferem entre si a $5 \%$ de significância. 
registrados níveis de acidez significativamente mais elevados quando comparado aos demais tratamentos a partir do $6^{\circ}$ dia (Tabela 2).

Segundo Wiley (1997), a acidez nos frutos pode aumentar em condições em que se adiciona ácido ao fruto durante a realização do processamento ou em condições de processos fermentativos. Neste trabalho verificou-se intensa proliferação de bolores e leveduras, logo no início do período de armazenamento, para o caldo de cana dos toletes que foram armazenados sob temperatura ambiente (Tabela 5). Esta intensa proliferação colaborou para a ocorrência do processo fermentativo e a produção de ácidos orgânicos, levando ao aumento excessivo da acidez e queda do $\mathrm{pH}$ do interior das células.

Para o teor de sólidos solúveis, foi observada uma queda significativa, a partir do $12^{\circ}$ dia de armazenamento, quando comparado ao $1^{\circ}$ dia, apenas para o caldo dos toletes sob temperatura ambiente (controle) (Tabela 3 ).

A queda do teor de sólidos está associada à intensa proliferação de microrganismos neste tratamento, principalmente leveduras e bolores, os quais consumiram os açúcares disponíveis através do processo de fermentação, diminuindo as concentrações de sólidos solúveis do caldo. Segundo Chitarra e Alves (2001), os açúcares constituem cerca de 85 a 90\% do teor de sólidos solúveis no caldo de cana-de-açúcar, o qual também representa a concentração de substâncias dissolvidas no conteúdo celular, entre as quais se destacam as vitaminas, os ácidos orgânicos e os pigmentos.

Nos demais tratamentos, o caldo obtido dos toletes sob refrigeração e congelamento apresentou queda gradual do SST, porém pouco significativa ao longo do período de armazenamento.

\subsection{Análise microbiológica}

Como pode ser visto na Tabela 4, as contagens obtidas para o caldo dos toletes não sanitizados apresentaram uma contaminação elevada, porém esperada para esse tipo de pro-

Tabela 2. Valores médios da acidez titulável do caldo de cana durante o armazenamento dos toletes sob três intervalos de temperatura.

\begin{tabular}{cccccc}
\hline $\begin{array}{c}\text { Temperatura de } \\
\text { estocagem }\left({ }^{\circ} \mathrm{C}\right)\end{array}$ & $1^{\circ}$ dia & $6^{\circ}$ dia & $12^{\circ}$ dia & $18^{\circ}$ dia & $24^{\circ}$ dia \\
\hline $22-25$ & $0,058^{\mathrm{Aa}}$ & $0,088^{\mathrm{Ab}}$ & $0,093^{\mathrm{Ab}}$ & $0,095^{\mathrm{Ab}}$ & $0,097^{\mathrm{Ab}}$ \\
4 & $0,057^{\mathrm{Aa}}$ & $0,065^{\mathrm{Aa}}$ & $0,069^{\mathrm{Aa}}$ & $0,070^{\mathrm{Aa}}$ & $0,072^{\mathrm{Aa}}$ \\
-20 & $0,065^{\mathrm{Aa}}$ & $0,050^{\mathrm{Aa}}$ & $0,049^{\mathrm{Aa}}$ & $0,056^{\mathrm{Aa}}$ & $0,065^{\mathrm{Aa}}$ \\
\hline
\end{tabular}

*Médias seguidas por letras distintas, maiúsculas nas linhas e minúsculas nas colunas, diferem entre si a $5 \%$ de significância.

Tabela 3. Médias de teor de sólidos solúveis (SST) do caldo de cana durante a armazenagem em diferentes temperaturas.

\begin{tabular}{clllll}
\hline $\begin{array}{l}\text { Temperatura de } \\
\text { estocagem }\left({ }^{\circ} \mathrm{C}\right)\end{array}$ & $1^{\circ}$ dia & $6^{\circ}$ dia & $12^{\circ}$ dia & $18^{\circ}$ dia & $24^{\circ}$ dia \\
\hline $22-25$ & $20,33^{\mathrm{Aa}}$ & $19,23^{\mathrm{ABab}}$ & $18,06^{\mathrm{Ba}}$ & $17,73^{\mathrm{Ba}}$ & $17,33^{\mathrm{Ba}}$ \\
4 & $19,93^{\mathrm{Aa}}$ & $19,20^{\mathrm{Ab}}$ & $19,03^{\mathrm{Aa}}$ & $18,93^{\mathrm{Aa}}$ & $18,06^{\mathrm{Aa}}$ \\
-20 & $20,10^{\mathrm{Aa}}$ & $19,76^{\mathrm{Aa}}$ & $19,19^{\mathrm{Aa}}$ & $18,96^{\mathrm{Aa}}$ & $18,26^{\mathrm{Aa}}$ \\
\hline
\end{tabular}

${ }^{\star}$ Médias seguidas por letras distintas, maiúsculas nas linhas e minúsculas nas colunas, diferem entre si a $5 \%$ de significância. duto (GALLO, 1989). A sanificação com solução $80 \mathrm{mg} \cdot \mathrm{L}^{-1}$ de cloro livre (Dicloro S-Triazinatriona Sódica Diadratada 3\%) foi eficiente na redução dessa contaminação natural, e as contagens dos três microrganismos caíram para níveis não detectáveis. No caso de leveduras e enterobactérias, a redução foi de 3 ciclos logaritmos, o que foi bastante eficiente.

As etapas de produção, bem como a contaminação inicial da matéria-prima, influenciam diretamente nos padrões de qualidade higiênico-sanitários dos produtos minimamente processados (WILEY, 1997). Nesse caso, considerando-se que os microrganismos em questão são fermentadores e deteriorantes do caldo de cana (JAY, 1992), o processo de sanificação é essencial para a obtenção de um caldo de cana extraído de toletes de cana minimamente processados, com elevado padrão de qualidade microbiológica.

Esta redução da carga microbiana do caldo extraído dos toletes sanitizados mostrou a eficiência do cloro orgânico sobre o hipoclorito de sódio. Leitão et al. (1981) verificaram uma redução da eficiência do hipoclorito de sódio frente à matéria orgânica vegetal, enquanto que Porto e Eiroa (2006) verificaram que o mesmo não ocorria com compostos clorados orgânicos, como o dicloroisocianurato de sódio, o qual foi utilizado como princípio ativo da solução clorada do presente trabalho.

Ao longo do período de armazenamento dos toletes, como era de se esperar, houve proliferação das leveduras, conforme mostra a Tabela 5 .

No caldo extraído dos toletes armazenados à temperatura ambiente $\left(22-25^{\circ} \mathrm{C}\right)$ foi observada uma intensa proliferação das leveduras no início do período de armazenamento, partindo de contagens não detectáveis $\left(<1,0 \mathrm{UFC} \cdot \mathrm{mL}^{-1}\right)$ no $1^{\circ}$ dia e superando o limite de detecção do método no $6^{\circ}$ dia (Tabela 5). Esse crescimento era esperado, pois as leveduras encontraram na cana-de-açúcar um substrato ótimo para seu crescimento, além disso, a temperatura ambiente é bastante propícia para seu desenvolvimento (GALLO, 1989).

Para o caldo extraído dos toletes sob refrigeração $\left(4{ }^{\circ} \mathrm{C}\right)$, a proliferação de leveduras foi bem menor, atingindo

Tabela 4. Contagens de bolores, leveduras e enterobactérias (UFC. $\mathrm{mL}^{-1}$ ) antes e após a sanitização com $200 \mathrm{mg} . \mathrm{L}^{-1}$ de cloro livre.

\begin{tabular}{lccc}
\hline Microrganismos & $\begin{array}{c}\text { Antes da } \\
\text { sanificação }\end{array}$ & $\begin{array}{c}\text { Após a } \\
\text { sanificação }\end{array}$ & $\begin{array}{c}\text { Redução } \\
(\text { ciclos log) }\end{array}$ \\
\hline Bolores & $0,7 \times 10(0,8)^{1}$ & $<1(0)$ & $>0,8$ \\
Leveduras & $9,9 \times 10^{2}(3,0)$ & $<1(0)$ & $>3,0$ \\
Enterobactérias & $2,1 \times 10^{3}(3,3)$ & $<1(0)$ & $>3,3$ \\
\hline
\end{tabular}

${ }^{1}$ Número entre parênteses $=$ logaritmo.

Tabela 5. Evolução das populações de leveduras (UFC. $\mathrm{mL}^{-1}$ ) no caldo de cana extraído de toletes minimamente processados armazenados sob diferentes temperaturas.

\begin{tabular}{lccccc}
\hline \multirow{2}{*}{ Temperatura } & \multicolumn{5}{c}{ Dias de armazenamento } \\
\cline { 2 - 6 } & $1^{\mathrm{o}}$ & $6^{\mathrm{o}}$ & $12^{\circ}$ & $18^{\circ}$ & $24^{\circ}$ \\
\hline Ambiente & $<1,0$ & $>2,5 \times 10^{7}$ & $>2,5 \times 10^{7}$ & $>2,5 \times 10^{7}$ & $>2,5 \times 10^{7}$ \\
Refrigeração & $<1,0$ & $2,2 \times 10^{3}$ & $\mathrm{t} 5,9 \times 10^{3}$ & $>2,5 \times 10^{7}$ & $>2,5 \times 10^{7}$ \\
Congelamento & $<1,0$ & $<1,0$ & $<1,0$ & $<1,0$ & $<1,0$ \\
\hline
\end{tabular}


$2,2 \times 10^{3}$ UFC. $\mathrm{mL}^{-1}$ no $6^{\circ}$ dia e mantendo-se nessa faixa até o $12^{\circ}$ dia de armazenamento. Somente no $18^{\circ}$ dia de armazenagem é que esta população ultrapassou o limite máximo detectável pelo método aplicado $\left(>250 \times 10^{5} \mathrm{UFC} . \mathrm{mL}^{-1}\right)$, limitando seu uso (Tabela 5).

Comparando-se a estocagem a $25^{\circ} \mathrm{C}$ com aquela sob refrigeração, observou-se que a vida útil dos toletes a $4{ }^{\circ} \mathrm{C}$ foi triplicada, uma vez que as contagens de leveduras levaram 18 dias para atingir o crescimento ocorrido em 6 dias sob temperatura ambiente (Tabela 5).

Para a população de bolores, foi observada uma intensa proliferação no caldo extraído dos toletes armazenados à temperatura ambiente $\left(22-25^{\circ} \mathrm{C}\right)$ a partir do $12^{\circ}$ dia de estocagem (>250 x $10^{5}$ UFC. $\left.\mathrm{mL}^{-1}\right)$, mantendo-se nesse nível até o final (Tabela 6).

Por outro lado, o caldo extraído dos toletes sob refrigeração $\left(4{ }^{\circ} \mathrm{C}\right)$ apresentou um desenvolvimento mais lento de bolores e somente no $24^{\circ}$ dia alcançou contagens elevadas (>2,5 x 107 UFC.mL ${ }^{-1}$ ) (Tabela 6). Segundo Lima (2000), os bolores e as leveduras são classificados como fungos psicrotróficos, crescendo de 0 a $40{ }^{\circ} \mathrm{C}$ e podendo se desenvolver a $4{ }^{\circ} \mathrm{C}$, embora o façam em velocidade bem menor.

A legislação vigente no Brasil não estabelece padrões microbiológicos para bolores e leveduras, porém quando as contagens superam $10^{3} \mathrm{UFC} \cdot \mathrm{mL}^{-1}$, em geral, já causam alterações sensoriais perceptíveis (JAY, 1992). A intensa proliferação de leveduras e bolores para o caldo de cana é sinal de deterioração do produto, já que estes microrganismos podem produzir enzimas que degradam os carboidratos, causando alterações desagradáveis no sabor e no aroma (LIMA, 2000).

Apenas as enterobactérias não se proliferaram sob os intervalos de temperatura avaliados, sendo que, para elas a sanificação foi suficiente para a sua eliminação e os sobreviventes não encontraram condições de multiplicação, devido à queda do pH ou à competição com as leveduras (Tabela 7).

Tabela 6. Evolução das populações de bolores (UFC. $\mathrm{mL}^{-1}$ ) no caldo de cana extraído de toletes minimamente processados e armazenados sob diferentes temperaturas.

\begin{tabular}{lccccc}
\hline \multirow{2}{*}{ Temperatura } & \multicolumn{5}{c}{ Dias de armazenamento } \\
\cline { 2 - 6 } & $1^{\circ}$ & $6^{\circ}$ & $12^{\circ}$ & $18^{\circ}$ & $24^{\circ}$ \\
\hline Ambiente & $<1,0$ & $<1,0$ & $>2,5 \times 10^{7}$ & $>2,5 \times 10^{7}$ & $>2,5 \times 10^{7}$ \\
Refrigeração & $<1,0$ & $2,3 \times 10^{3}$ & $10,8 \times 10^{3}$ & $12,3 \times 10^{3}$ & $>2,5 \times 10^{7}$ \\
Congelamento & $<1,0$ & $<1,0$ & $<1,0$ & $<1,0$ & $<1,0$ \\
\hline
\end{tabular}

Tabela 7. Evolução das populações de enterobactérias (UFC.mL $L^{-1}$ ) no caldo de cana extraído de toletes minimamente processados e armazenados sob diferentes temperaturas.

\begin{tabular}{lccccc}
\hline \multirow{2}{*}{ Temperatura } & \multicolumn{5}{c}{ Dias de armazenamento } \\
\cline { 2 - 6 } & $1^{\circ}$ & $6^{\circ}$ & $12^{\circ}$ & $18^{\circ}$ & $24^{\circ}$ \\
\hline Ambiente & $<1,0$ & $<1,0$ & $<1,0$ & $<1,0$ & $<1,0$ \\
Refrigeração & $<1,0$ & $<1,0$ & $<1,0$ & $<1,0$ & $<1,0$ \\
Congelamento & $<1,0$ & $<1,0$ & $<1,0$ & $<1,0$ & $<1,0$ \\
\hline
\end{tabular}

Assim, pode-se concluir que a armazenagem na temperatura ambiente não foi adequada para a estocagem de toletes de cana minimamente processados, devido à baixa qualidade microbiológica apresentada logo no início do período de armazenamento, demonstrando que os toletes de cana sob essa condição devem ser consumidos imediatamente.

No tratamento sob congelamento dos toletes, $\mathrm{a}-20^{\circ} \mathrm{C}$, foi verificada a inibição do crescimento microbiano, como observado nas Tabelas 5 e 6, o que é esperado, pois o metabolismo microbiano é interrompido e algumas células podem morrer (JAY, 1992). Assim, essa seria uma alternativa adequada para a estocagem prolongada dos toletes de cana, uma vez que os mesmos atravessaram todo o período de armazenamento avaliado (24 dias), inalterados sob o ponto de vista microbiológico.

\section{Conclusões}

O caldo de cana-de-açúcar, extraído de toletes armazenados sob congelamento, obteve alterações físico-químicas pouco significativas e população microbiana baixa e estável por 24 dias, sendo essa recomendada para a estocagem por períodos prolongados. Por outro lado, a temperatura ambiente não foi adequada à estocagem de toletes de cana minimamente processados, uma vez que se observou intensa proliferação de leveduras em apenas 6 dias. A refrigeração dos toletes de cana manteve a qualidade microbiológica do caldo dentro dos padrões aceitáveis, por até 12 dias.

\section{Referências bibliográficas}

CARVALHO, C. R. L. et al. Análises químicas de alimentos. Campinas: ITAL, 1990. 121 p. (Manual Técnico).

CARUSO, J. G. B.; CAMARGO, R. Microbiologia de alimentos. In: CAMARGO, R. Tecnologia dos produtos agropecuáriosalimentos. São Paulo: Nobel, 1984, p. 35-49.

CHITARRA, A. B.; ALVES, R. E. Tecnologia de pós-colheita para frutos tropicais. Fortaleza: Frutal-Sindifruta, v1, 2001.

GALLO, C. R. Determinação da microbiota bacteriana de mosto e de dornas de fermentação alcoólica. Campinas, 1989. 388 p. Tese (Doutorado) - Faculdade de Engenharia de Alimentos, Universidade de Campinas.

GONZÁLEZ, M.; LOBO, M. G. Estado actual de los productos mínimamente procesados en España. In: ENCONTRO NACIONAL SOBRE PROCESSAMENTOS MÍNIMOS DE FRUTAS E HORTALIÇAS, 4, 2006, São Pedro. Palestras, Recados, Fluxogramas e Oficinas... Piracicaba: USP/ESALQ, 2006. p. 77-92.

IFPA - International Fresh-cut Produce Association. Disponível em: <http://www.fresh-cuts.org>. Acesso em: 15 jun. 2006.

JAY, J. M. Microbiologia moderna de los alimentos. Zaragoza : Acribia, 1992. $804 \mathrm{p}$.

LEITÃO, M. F. F et al. Eficiência de desinfetantes na redução da contaminação bacteriana da alface (Lactucca sativa). Coletânea do ITAL, v. 18, n. 2, p. 201-226, 1981.

LIMA, L. C. O. Processamento mínimo de kiwi e mamão. In: ENCONTRO NACIONAL SOBRE PROCESSAMENTO DE FRUTAS E HORTALIÇAS, 2, 2000, Viçosa. Palestras... Viçosa: Universidade Federal de Viçosa, 2000. p. 95-109.

PORTO, E.; EIROA, M. N. U. Avaliação da eficiência de sanificantes e do uso de atmosfera modificada sobre Listeria monocytogenes 
inoculada em alfaces. Brazilian Journal of Food Technology, v. 9, n. 3, p. 177-183, 2006.

VANDERZANT, C.; SPLiTTSTOESSER, D. F. Compendium of methods for the microbiological examination of foods. Washington: American Public Health Association, 1992. 1219 p.
WILEY, R. C. Frutas y hortalizas minimamente processadas y refrigeradas. Zaragoza: Acribia, 1997. $362 \mathrm{p}$.

ZONTA, E. P.; MACHADO, A. A. SANEST - Sistema de Análise Estatística Para Microcomputadores. Pelotas: Universidade Federal de Pelotas, 1985. 1 v. 